\title{
Endothelial \\ keratoplasty: is \\ Descemet membrane endothelial keratoplasty the Holy Grail of lamellar surgery? No
}

Eye (2017) 31, 1333-1336; doi:10.1038/eye.2017.51; published online 21 April 2017

Posterior lamellar surgery has transformed the management of corneal endothelial disease due to faster visual rehabilitation, minimal refractive change, and maintenance of the ocular structural integrity compared full thickness keratoplasty. Although Descemet's membrane endothelial keratoplasty (DMEK) appears to offer an anatomical repair for endothelial pathology, replacing only endothelium and Descemet's membrane without any posterior stroma, ${ }^{1}$ it has yet to supersede Descemet's stripping endothelial keratoplasty (DSEK) and its variations; ultrathin Descemet's stripping automated endothelial keratoplasty (UT-DSAEK), 2,3 thin manual Descemet stripping keratoplasty (TMDSEK), ${ }^{4}$ and pre-Descemet's endothelial keratoplasty (PDEK) ${ }^{5}$ as the mainstay the treatment of Fuchs endothelial dystrophy or bullous keratopathy. The main reason for this is that DMEK is technically more challenging, requiring prolonged surgical time, associated with a steeper learning curve and possibly more potential complications. ${ }^{6,7}$

\section{Intraoperative complications}

The technical challenges with DMEK initially occur at graft harvesting where rates of tissue loss and need to convert to DSEK have been reported to be between 4.2 and $8 \%$ of cases. 8,9 Melles' groups reported a higher rate $(17.3 \%)$ of moderate intraocular complications such as failure of graft to unroll in the anterior chamber, persistent Descemet's membrane after Descemetorhexis and hyphaema. ${ }^{10}$

\section{Post-operative complications}

The reported DMEK graft detachment rates and rebubbling rates vary in the literature. In a particular study, the rebubbling rate was as high as $62 \% .{ }^{8}$ Melles' group report a $17.3 \%$ graft detachment rate with $5.3 \%$ requiring intervention such as rebubbling $(2.9 \%)$ or repeat DMEK, DSEK, or penetrating keratoplasty in $2.4 \%$ of cases. ${ }^{10}$ Although these numbers are improved in the hands of experienced DMEK surgeons, they are still higher than complication rates reported for DSEK, UT-DSEK, TMDSEK, and PDEK. $4,5,10-12$ In a comparative study, graft detachment requiring rebubbling occurred in $3.2 \%$ of DSAEK cases and $8.6 \%$ of DMEK cases. ${ }^{12}$

The deleterious effects of rebbubling and additional surgical manipulation on the graft have been established both in vitro and in vivo. ${ }^{13,14}$

Primary graft failure, defined as the absence of corneal clearing despite graft adherence, has been reported with great variation between studies. Guerra et al ${ }^{8}$ reported a DMEK primary graft failure rate of $8 \%$. Conversely, Satue et al ${ }^{10}$ report a lower rate of primary graft failure $(0.22 \%)$ in 450 consecutive cases of DMEK. Hamzaoglu et al ${ }^{12}$ reported a $5.7 \%$ rate of primary graft failure attributed to difficult surgical manipulation. In this last study, no graft failures occurred in the DSAEK group.

The rate of peri-operative problems, such as dissection failure, need for excessive tissue handling, which in turn risks graft viability, and post-operative problems, such as persistent graft folds and primary failure, is much higher in DMEK compared to DSEK and can affect graft survival and visual quality. It is also questionable if these challenges can merely be 
attributed to a steep learning curve or is DMEK inherently more problematic? ${ }^{15}$

In contrast to these intraoperative and post-operative challenges faced by the surgeon during and after DMEK surgery, a number of techniques have been described for the safe and reliable dissection of ultrathin DS(A)EK grafts. $^{2,4,5,16,17}$

Busin et $a l^{2}$ described a double-pass technique that allows the creation grafts with central thickness of $100 \mu \mathrm{m}$ or less in $78.82 \%$ of cases and $130 \mu \mathrm{m}$ or less in $95.6 \%$ of the cases. The authors reported intraoperative complications, such as difficulty in graft dissection, in $7.2 \%$ of cases and yet only $2.1 \%$ of tissue was discarded as a result. Simple technique modifications, such as eccentric punching or manual finalisation of the dissection, allowed the vast majority of the cases to be salvageable. ${ }^{2}$

Rosa et al $^{16}$ described the ultrathin $<100 \mu \mathrm{m}$ DSAEK in 25 cases with two sequential cuts the first with a femtosecond laser and the second using a $300 \mu \mathrm{m}$ microkeratome head. They reported no perforations or other problems during tissue preparation and a LogMar VA of 0.116 -months post operatively.

Tsatsos et $a l^{4}$ described a manual technique, TMDSEK, which purposely encourages and utilises temporary stromal swelling. Increased corneal stromal thickness during dissection allows for ultrathin DSEK graft creation without greatly increasing the risk of a graft perforation or button-hole creation. They reported a mean graft thickness of $90.7 \mu \mathrm{m}$ 1-month post operatively.

Agarwal et $a l^{5}$ described PDEK, a technique that employs pneumatic dissection rendering a thin corneal graft, much like DSEK graft which consists of endothelium, Descemet's membrane, and a predescemetic (PDL-Dua's layer) level and a mean graft thickness of $28 \mu \mathrm{m}$. In PDEK, the total thickness of the PDL together with the endothelium and DM is less than the overall thickness of the DSEK and UT-DSAEK graft. The sparcity or even absence of keratocytes in the central PDL tissue may also contribute to reduced haze, as air cleavage creates a smooth plane and keratocyte activity can be associated with abnormal collagen deposition and haze. The mean graft diameter obtained in PDEK is smaller than in DMEK grafts possibly due to the difficulty in the separation of the PDL in the peripheral cornea. Thus, fewer endothelial cells are transplanted in comparison with other techniques, however, this may be compensated for by reduced cell loss related to manipulation of tissue, especially during unrolling and attachment to the recipient bed. ${ }^{5}$

For corneal surgeons, accessibility to PDEK may be better, because preparation of the donor tissue can be done from preserved corneo-scleral rims, does not require expensive instrumentation, and is not as technically challenging as preparation and manipulation of DMEK tissue. Nevertheless, conversion of PDEK to DMEK may be required to prevent wastage of donor tissue in cases of type II bubble creation.

Large number of patients and longer follow-up periods will be required to confirm the accuracy of the above and to establish a place for PDEK in corneal transplantation surgery.

\section{Visual outcome}

One of the greatest benefits of posterior lamellar keratoplasty is the fast visual rehabilitation and improved visual outcomes with little effect on astigmatism. ${ }^{8,9,18}$ Some authors would argue that visual outcomes following DMEK are superior to other posterior lamellar techniques. ${ }^{12,19}$ A 5-year prospective study by Wacker et $a l^{20}$ reported continued visual improvement in DSEK patients over 5 years and over half the cohort with vision of 0.1 LogMar or better. The challenges when interpreting long-term data in DSEK is that the technique itself has evolved and we have been able to achieve thinner DSEK grafts more consistently. ${ }^{4}$ Mean graft thickness in Wacker's cohort was $155 \mu \mathrm{m}$, which may or not be representative depending on the institution and technique employed. ${ }^{20}$ Busin et al ${ }^{11}$ reported 2-year outcomes following UT-DSAEK (mean graft thickness of $78.28 \mu \mathrm{m}$ ) with mean BSCVA at 24 months of 0.04 LogMar, with $48.8 \%$ of patients in the entire cohort achieving a visual acuity of $20 / 20$ or better and suggested that outcomes with UT-DSAEK were comparable to DMEK.

Although DMEK offers faster visual rehabilitation compared to DSEK or DSAEK, overall performance seems to remain akin. However, the advantageous fast visual rehabilitation is also offered with other techniques such as PDEK. 5

\section{Use in complex cases and one chamber eyes}

Both DSEK or DSAEK and PDEK have been successfully used in aphakic or AC IOL eyes and heavily scarred host corneas. ${ }^{21-24}$ Although there appears to be some success (limited by high rebubbling and secondary graft failure rates) with DMEK, DSEK is generally considered the preferred technique in such complex cases. ${ }^{25,26}$ Although PDEK has not been used widely in complex cases, early results appear very promising. ${ }^{24}$

\section{Limitations of graft harvesting}

DMEK graft harvesting can be at least at its initial stages very challenging. ${ }^{7}$ For this reason, a number of useful tricks have been proposed to facilitate the harvesting process, ${ }^{27,28}$ graft insertion, orientation, and correct placement in the host. ${ }^{29}$ This includes the use of older 
donor eyes as they allow safer DMEK harvesting with less risk of endothelial rip and the easier opening of the endothelial roll inside the host's anterior chamber. This would be potentially linked to donor tissue waste, which can easily and even preferentially be averted in PDEK, as PDEK has been described in younger and even infant donor corneas. ${ }^{30}$

\section{Rejection}

Endothelial graft rejection rates have been reported to be a lot higher with early DSAEK compared with DMEK. UT-DSAEK has been shown to have low rejection rates $(2.8 \%) .8,9,31,32$ This compared to the rejection rates of between 1 and 5.7\% shown for DMEK at year 1 after surgery suggests a similarly low incidence of immunologic rejection seen in both UT-DS(A)EK and DMEK grafts. $8,9,32$

\section{Concluding remarks}

It is without question that endothelial keratoplasty has transformed corneal surgery and most importantly the visual quality we can offer our patients with endothelial disease. Emerging techniques and technologies have allowed us to push the boundaries and deliver increasingly thinner grafts. DMEK offers a more anatomical correction but with it come numerous surgical challenges. The evidence regarding visual outcomes at 'end point' is similar between all techniques leading to the question 'is it worth it?' The greatest question is whether there is still a role for DSEK and DSAEK? To which the evidence suggests that there is both as a primary procedure or rescue procedure. To answer the question 'Has DMEK taken over?' the answer is no, or at least, not yet.

\section{Conflict of interest}

The authors declare no conflict of interest.

\section{References}

1 Melles GR, Lander F, Rietveld FJ. Transplantation of Descemet's membrane carrying viable endothelium through a small scleral incision. Cornea 2002; 21: 415-418.

2 Busin M, Patel AK, Scorcia V, Ponzin D. Microkeratomeassisted preparation of ultrathin grafts for Descemet stripping automated endothelial keratoplasty. Invest Ophthalmol Vis Sci 2012; 53(1): 521-524.

3 Hsu M, Hereth WL, Moshirfar M. Double-pass microkeratome technique for ultra-thin graft preparation in Descemet's stripping automated endothelial keratoplasty. Clin Ophthalmol 2012; 6: 425-432.

4 Tsatsos M, Konstantopoulos A, Hossain P, Anderson D. Presoaking with BSS used for thin manually dissected DSEK
(TMDSEK): a viable option for thin DSEK. Eye 2014; 28(6): 701-704.

5 Agarwal A, Dua HS, Narang P, Kumar DA, Agarwal A, Jacob $\mathrm{S}$ et al. Pre-Descemet's endothelial keratoplasty (PDEK). Br J Ophthalmol 2014; 98(9): 1181-1185.

6 Terry MA. Endothelial keratoplasty: why aren't we all doing Descemet membrane endothelial keratoplasty? Cornea 2012; 31: 469-471.

7 Price MO, Price FW Jr. Descemet's membrane endothelial keratoplasty surgery: update on the evidence and hurdles to acceptance. Curr Opin Ophthalmol 2013; 24(4): 329-335.

8 Guerra FFP, Anshu A, Price MO, Giebel AW, Price FW. Descemet's membrane endothelial keratoplasty prospective study of 1-year visual outcomes, graft survival, and endothelial cell loss. Ophthalmology 2011; 118: 2368-2373.

9 Price MO, Giebel AW, Fairchild KM, Price FW Jr. Descemet's membrane endothelial keratoplasty: prospective multicenter study of visual and refractive outcomes and endothelial survival. Ophthalmology 2009; 116: 2361-2368.

10 Satue M, Rodriguez-Calvo-de-Mora M, Naveiras M, Cabrerizo J, Dapena I, Melles GRJ. Standardization of the Descemet membrane endothelial keratoplasty technique: outcomes of the first 450 consecutive cases. Arch Soc Esp Oftalmol 2015; 90(8): 356-264.

11 Busin M, Madi S, Santorum P, Scorica V, Beltz J. Ultrathin Descemet's stripping automated endothelial keratoplasty with the microkeratome double -pass technique: two-year outcomes. Ophthalmology 2013; 120(6): 1186-1194.

12 Hamzaoglu EC, Straiko MD, Mayko ZM, Sales CS, Terry MA. The first 100 eyes of standardized Descemet stripping automated endothelial keratoplasty versus standardized Descemet membrane endothelial keratoplasty. Ophthalmology 2015; 122(11): 2193-2199.

13 Kopsachilis N, Tsaousis KT, Tsinopoulos IT, Welge-Luessen U. Air toxicity for primary human-cultured corneal endothelial cells: an in vitro model. Cornea 2013; 32(4): e31-e35.

14 Maier AK, Gundlach E, Schroeter J, Klamann MK, Gonnermann J, Riechardt AI et al. Influence of the difficulty of graft unfolding and attachment on the outcome in Descemet membrane endothelial keratoplasty. Graefes Arch Clin Exp Ophthalmol 2015; 253(6): 895-900.

15 Patel SV. Graft survival and endothelial outcomes in the new era of endothelial keratoplasty. Exp Eye Res 2012; 95(1): $40-47$.

16 Silva Rosa AM, Silva MF, Quadrado MJ, Costa E, Marques I, Murta JN. Femtosecond laser and microkeratome-assisted Descemet stripping endothelial keratoplasty:first clinical results. Br J Ophthalmol 2013; 97(9): 1104-1107.

17 Jones YJ, Goins KM, Sutphin JE, Mullins R, Skeie JM. Comparison of the femtosecond laser (IntraLase) versus manual microkeratome (Moria ALTK) in dissection of the donor in endothelial keratoplasty: initial study in eye bank eyes. Cornea 2008; 27(1): 88-93.

18 Anshu A, Price MO, Price FW. Risk of corneal transplant rejection significantly reduced with Descemet's membrane endothelial keratoplasty. Ophthalmology 2012; 119: 536-540.

19 Green M, Wilkins MR. Comparison of early surgical experience and visual outcomes of DSAEK and DMEK. Cornea 2015; 34(11): 1341-1344.

20 Wacker K, Baratz KH, Maguire LJ, McLaren JW, Patel SV. Descemet stripping endothelial keratoplasty for fuchs endothelial corneal dystrophy: five-year results of a prospective study. Ophthalmology 2016; 123(1): 154-160. 
21 Beltz J, Busin M. Descemet stripping automated endothelial keratoplasty in a case with a posteriorly fixate iris-claw intraocular lens. Cornea 2012; 31(1): 96-97.

22 Beltz J, Madi S, Scorcia V, Busin M. Descemet stripping automated endothelial keratoplasty for endothelial decompensation in buphthalmos. Am J Ophthalmol 2013; 156(3): 608-615.

23 Jacob S, Agarwal A, Agarwal A, Narashimhan S, Kumar DA, Sivagnanam $S$. Endoilluminator-assisted transcorneal illumination for Descemet membrane endothelial keratoplasty: enhanced intraoperative visualization of the graft in corneal decompensation secondary to pseudophakic bullous keratopathy. J Cataract Refract Surg 2014; 40(8): 1332-1336.

24 Narang P, Agarwal A, Dua HS, Kumar DA, Jacob S, Agarwal A. Glued intrascleral fixation of intraocular lens with pupilloplasty and pre-Descemet endothelial keratoplasty: a triple procedure. Cornea 2015; 34(12): 1627-1631.

25 Liarakos VS, Ham L, Dapena I, Tong CM, Quilendrino R, Yeh RY et al. Endothelial keratoplasty for bullous keratopathy in eyes with anterior chamber intraocular lens. J Cataract Refract Surg 2013; 39(12): 1835-1845.

26 Weller JM, Tourtas T, Kruse FE. Feasibility and outcome of Descemet membrane endothelial keratoplasty in complex anterior segment and vitreous disease. Cornea 2015; 34(11): 1351-1357.

27 Menzel-Severing J, Salla S, Plum WJ, Tourtas T, Fuchsluger T, Schötzer-Schrehardt U et al. Instrument to enhance visualization of Descemet membrane during graft preparation for DMEK surgery. Cornea 2016; 35(6): 904-907.

28 Salvalaio G, Parekh M, Ruzza A, Ferrari S, Camposampiero D, Ponzin D. DMEK lenticule preparatioin from donor corneas using a novel 'SubHyS' technique followed by anterior corneal dissection. Br J Ophthalmol 2014; 98(8): 1120-1125.

29 Veldman PB, Dye PK, Holiman JD, Mayko ZM, Salies CS, Straiko MD et al. The S-stamp in Descemet membrane endothelial keratoplasty safely eliminates upside-down graft implantation. Ophthalmology 2016; 123(1): 161-164.

30 Agarwal A, Agarwal A, Narang P, Kumar DA, Jacob S. Pre-Descemet endothelial keratoplasty with infant donor corneas: a prospective analysis. Cornea 2015; 34(8): 859-865.

31 Lee WB, Jacobs DS, Musch DC, Kaufma SC, Reinhart WJ, Shtein RM. Descemet's stripping endothelial keratoplasty: safety and outocomes: a report by the American Academy of Ophthalmology. Ophthalmology 2009; 116: 1818-1830.

32 Anshu A, Price MO, Tan DT, Price FW Jr. Endothelial keratoplasty: a revolution in evolution. Surv Ophthalmol 2012; 57: 236-252.

$$
\begin{array}{r}
\text { M Tsatsos }{ }^{1,2,3} \text {, VS Liarakos }{ }^{4}, \text { C MacGregor }{ }^{2}, \\
\text { I Athanasiadis }{ }^{1} \text {, ET Detorakis }{ }^{5}, \text { MM Moschos }{ }^{3}, \\
\text { P Hossain }{ }^{2,6} \text { and DF Anderson }{ }^{2,6}
\end{array}
$$

${ }^{1}$ Royal Eye Infirmary, Dorset County Hospital NHS Foundation Trust, Dorchester, UK

${ }^{2}$ Southampton University Hospital, Southampton, UK

${ }^{3}$ Aristotelian University of Thessaloniki, Thessaloniki,

Greece

${ }^{4}$ Netherlands Institute for Innovative Ocular Surgery,

Rotterdam, The Netherlands

${ }^{5}$ Department of Ophthalmology, University Hospital of Heraklion, Heraklion, Greece

Correspondence: M Tsatsos, Royal Dorset Infirmary, Dorset County Hospital, Williams Ave, Dorchester, UK

Tel: 01305 251150;

Fax: 01305255374.

E-mail: michaeltsatsos@gmail.com

${ }^{6}$ These authors contributed equally to this work. 